ТКАЧЕНКО

Сергій Анатолійович tkachenko26091980@gmail.com

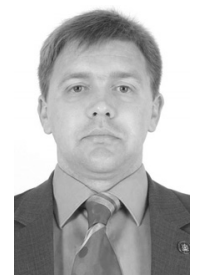

д.е.н., дочент, ректор, ВНЗ «Міжнародний технологічний університет «Миколаӥвська політехніка»
ТКАЧЕНКО

В'ячеслав Анатолійович grandlist1986@gmail.com

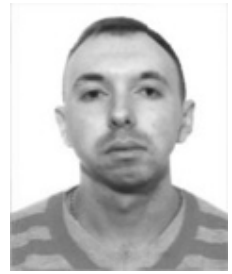

викладач, «Міжнародний технологічний університет «Миколаївська політехніка»
ТКАЧЕНКО

Світлана Вікторівна desvetlana66@gmail.com

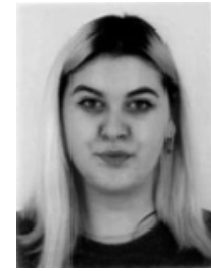

викладач, «Міжнародний технологічний університет «Миколаївська політехніка»

Удк 657

\title{
DESCRIPTION OF THE CRITERION OF THE EFFECTIVENESS OF THE FUNCTION OF INTEGRATED ECONOMIC ANALYSIS (EVALUATION) IN FUNCTIONALLY DEVELOPED METHODS OF STRATEGIC REGULATION OF SPECIAL PURPOSE BY ENTERPRISES
}

TKACHENKO Serhii Anatoliiovych - Doctor of Economics, Associate Professor, Rector, Higher Educational Institution «International Technology University "Mykolaiv Polytechnic"»

TKACHENKO Viacheslav Anatoliiovych - lecturer, Higher Educational Institution «International Technology University "Mykolaiv Polytechnic"»"

TKACHENKO Svitlana Viktorivna - lecturer, Higher Educational Institution «International Technology University "Mykolaiv Polytechnic"»"

Аргументировано, что при характеристике цуели интегрированного экономического анализа и оценки весьма важно чётко сформулировать её критерии качества, то есть те показатели, по которым можно судить о степени и полноте осуществления цели. Обосновано, что единственно правильным путём применительно к интегрированному экономическому анализу, оченке функиионально развитых систем контроля специального назначения предприятиями будет поиск критерия качества на основе общего методологического подхода. Доказано, требование относительно возможности установления критерия качества функционирования при создании в функционально развитьх системах управления специального назначения предприятиями,экономического анализа выполняется сполна.

$$
* * *
$$

Аргументовано, щуо у характеристиці мети аналізу досить важливо чітко сформулювати ї̈ критерії якості, тобто ті показники, за якими можливо судити про ступінь та повноту здійснення мети. Господарська політика вимагає отримання для цілей системи управління всебічної інформації при мінімальних витратах на ї̈ формування $і$ перетворення. Виходячи із иієї посилки необхідни логічним елементом системного підходу у процесі створення підсистеми аналізу повинно бути визначення такого критерію якості ї̈ функиіонування, за величиною якого можливо було б судити про перевагу того або іншого варіанта побудови функиіі. Якщо генеральна мета підсистеми адміністрування виражається ї̈ цільовою функцією, тоді критерій якості являє чисельне вираження ияільової функиіі. Водночас слід зазначити той факт, изо вибір критерію якості - показника, який дозволяє судити про ступінь та повноту реалізачії мети, представляє на даний час одну із найбільш складних і дискусійних проблем. У формуванні такого критерію якості як для усього виробництва у иілому, так й для різних систем управління та їх частин виникають значні трудноші методологічного характеру. Саме изим можливо пояснити той факт, щуо проектувальники систем управління дотепер не мають загальновизнаного критерію якості, створювати системи управління, без якого дуже важко. Такий стан змушує розробників систем управління у кожному конкретному випадку висувати якісь свої критерії якості, далеко не завжди задовільні за змістом, шзо у кінцевому підсумку нерідко негативно позначається на особливості генерування конструкцій адміністрування. Обгрунтовано, щзо єдино правильним шляхом стосовно функиї аналізу систем контролю підприсмствами буде пошук критерію якості на основі загального методологічного підходу. Доведено, щзо ключова вимога відносно можливості установлення критерію якості функціонування у створенні у системах регулювання підприємствами господарського аналізу виконується сповна.

$$
* * *
$$

It is argued that, when characterizing the purpose of the analysis, it is important to clearly formulate its quality criteria, that is, the indicators by which it is possible to judge the degree and completeness of the purpose. Business policy requires the receipt of comprehensive information for the purposes of a comprehensive information management system with minimal cost of its formation and transformation. Based on this premise, a necessary logical element of a systematic approach in the process of creating a 
subsystem of analysis should be to determine such a criterion for the quality of its functioning, the magnitude of which could be judged on the advantage of one or another variant of function construction. If the general purpose of the administration subsystem is expressed by its objective function, then the quality criterion is the numerical expression of the objective function. It should be noted that the choice of quality criterion - an indicator that allows to judge the degree and completeness of the goal -is currently one of the most difficult and debatable problems. The formation of such a quality criterion, both for the whole production as a whole, and for various management systems and their parts, raises considerable methodological difficulties. This can be explained by the fact that designers of control systems still do not have a generally recognized quality criterion, to create control systems without which it is very difficult. This situation forces the developers of control systems in each case to put forward some of their quality criteria, not always satisfactory in content, which, in the end, often has a negative impact on the features of the generation of administration structures. It is substantiated that the only correct way to analyze the function of control systems of enterprises will be to find a quality criterion based on a common methodological approach. Proved a key requirement concerning the possibility of establishing functioning quality criterion when creating control systems in enterprises, economic analysis performed in full, rest.

Ключевые слова: интегрированный экономический анализ и оценка, критерий эффективности, подсистема, предприятие, система управления, специфическое назначение, функиионально развитой, фунциклирование, цель

Ключові слова: інтегрований господарський аналіз та оцінка, критерій ефективності, об єенання, підприємство, підсистема, система регулювання, спеціальне призначення, функиіонально розвинутий, функціонування, функиія

Keywords: functional development, functioning, industrial enterprise, integrated economic analysis and assessment, performance criterion, research and production association, special appointment, strategic management system, target

\section{ВСТУПЛЕНИЕ}

При характеристике цели подсистемы (функции) аналитической обработки технико-экономических информационных данных (интегрированного экономического анализа и оценки) весьма важно чётко определить её критерии производительности (качества), то есть те показатели, по которым можно судить о степени и полноте реализации цели. Производственнохозяйственная политика требует получения для целей системы стратегического управления всесторонней информации при минимальных затратах на её формирование и преобразование. Исходя из этой посылки необходимым логическим элементом системного подхода в процессе создания подсистемы (функции) аналитической обработки технико-экономических информационных данных (интегрированного экономического анализа, оценки) должно быть определение такого критерия продуктивности её функционирования, по величине которого можно было бы судить о предпочтительности того или иного варианта (плана) построения подсистемы.

Если генеральная цель подсистемы управления выражается её целевой функцией, то критерий продуктивности (качества) представляет численное выражение целевой функции. При этом следует отметить тот факт, что выбор критерия производительности - показателя, позволяющего судить о степени и полноте реализации цели, - представляет в настоящее время одну из наиболее сложных и дискуссионных проблем. При формировании такого критерия оптимальности (качества) как для всего производства в целом, так и для различных систем управления и их частей возникают значительные трудности теоретико-методологического характера. Именно этим можно объяснить тот факт, что проектировщики систем управления до сих пор не имеют общепризнанного критерия эффективности, создавать функционально развитые системы стратегического управления специального назначения, без которого весьма затруднительно. Такое положение заставляет разработчиков систем управления в каждом конкретном случае выдвигать какие-то свои критерии продуктивности (качества), далеко не всегда удовлетворительные по содержанию, что, в конечном счёте, нередко отрицательно сказывается на специфике особенности генерируемых конструкций администрирования.

В настоящее время в литературных трудах и научноисследовательских работах по вопросам управления $[1,2]$ предложен целый ряд подходов к определению общих и частных критериев производительности. Рассмотрим некоторые критерии продуктивности (качества), оценивающие особенность информационных систем управления: I. Критерий минимума суммы затрат на производство информации и потерь в сфере управления от её неполноты и недостаточно высокого качества. II. Критерий максимума суммарной ценности получаемых данных при заданных затратах различных ресурсов. III. Критерий минимума суммы затрат всех ресурсов при заданной программе выпуска методы информации, то есть при заданных номенклатуре выходных показателей и характеристиках, их периодичности, срочности, достоверности.

Исследование приведённых критериев оптимальности (качества) с точки зрения приемлемости их для подсистемы (функции) аналитической обработки технико-экономических информационных данных (интегрированного экономического анализа и оценки) показывает, что два первых из них в теоретическом отношении имеют определенное преимущество и приоритет перед третьим, так как они рассматривают систему информации, во-первых, как часть системы управления и, во-вторых, как часть всей системы производственно-хозяйственной деятельности. Тем не менее, в силу ряда причин их применение в реально существующих в промышленных предприятиях, на научнопроизводственных объединениях условиях практически невозможно и лишено значительного смысла. Дело в том, что если затраты на создание и развитие систем управления могут быть при действующей организации бухгалтерского учёта и отчётности отражены достаточно точно, то потери от неполноты, некачественности информации ввиду отсутствия методов их количественной оценки учесть абсолютно немыслимо. Невозможно также из-за отсутствия соответствующего 
взвешенного аппарата измерить в достаточно корректном виде ценность используемых в учении управления информационных данных.

Поэтому, с точки зрения практического применения, на наш взгляд, более предпочтительным следует признать третий критерий оптимальности (качества), который ставит в центр проблемы процесс производства информации, а также величину затрат ресурсов. Однако, несмотря на то, что критерий минимума затрат значительно упрощает проблему оценки качества создаваемых систем управления, следует отметить и один его существенный недостаток - он не отражает подлинной эффективности системы. Кроме того, все три рассмотренных выше критерия оптимальности (качества), выражаясь абсолютной величиной, далеко не всегда приемлемы для сравнительной оценки параллельно создаваемых, функционирующих систем регулирования.

\section{ЦЕЛЬ РАБОТЫ}

В этой связи представляется, что единственно правильным путём применительно к подсистеме (функции) аналитической обработки технико-экономических информационных данных (интегрированного экономического анализа и оценки) функционально развитых систем стратегического управления специального назначения промышленными предприятиями и научно-производственными объединениями будет поиск критерия качества (производительности) на базе общего теоретико-методологического подхода.

\section{МЕТОДЫ ИССЛЕДОВАНИЯ}

Теоретико-методологической основой данной научной статьи выступает диалектический метод, узловые позиции теории анализа, оценки, управления. В процессе освидетельствования использовались методы: абстрактно-логический (для философского обобщения и формулирования результатов); монографический (при трактовке резонных метод анализа, контроля, оценки).

\section{РЕЗУЛЬТАТЫ}

Многолетняя практика создания функционально развитых систем стратегического управления специиального назначения промышленными предприятиями, учёно-производственными объединениями свидетельствует, что существуют два понятия, группирующих всё многообразие экономического эффекта: экономический эффект в стоимостном измерении, получаемый в системе управления $\left(E_{1}\right)$, и экономический эффект в стоимостном измерении, получаемый в управляемой системе $\left(E_{2}\right)$. Первая группа экономического эффекта обусловлена главным образом применением более прогрессивных технических средств и степенью реализации возможностей новой технологии обработки информационных данных. В практических условиях исчисление экономического эффекта этого вида не вызывает каких-либо значительных затруднений. Вторая группа вызвана воздействием информации, полученной с помощью передовых технических средств, новой технологии обработки данных, на производственный процесс. Этот вид экономического эффекта характеризует управляемую систему и возникает в тех случаях, когда принимаемое на основе результатной информации задачи управляющее решение приводит к интенсификации деятельности управляемой системы. К нему относится уменьшение затрат или получение дополнительных выгод качественного и количественного характера на том участке производственного процесса, где используются результаты решения задачи. Следует отметить, что экономический эффект данного вида не будет получен в случае непринятия на основе результатной информации задачи соответствующего администрирующего урегулирования.

Именно полученный экономический эффект (рентабельность) указанных выше двух видов, по нашему мнению, и должен быть положен в основу расчёта критерия эффективности как создаваемых систем управления вообще, так и подсистемы (функции) аналитической обработки технико-экономических информационных данных (интегрированного экономического анализа и оценки) функционально развитых систем стратегического управления специального назначения предприятиями промышленности и учёно-производственными объединениями, который, в частности, безусловно возможно представить в следующей своеобразной конструкции, формула (1):

$$
C_{e f}=\frac{E_{1}+E_{2}}{S}
$$

где $C_{e f}$ - коэффициент экономической эффективности (рентабельности) создаваемой подсистемы управления; $S$ - затраты в стоимостном измерении на проектирование, создание, функционирование подсистемы регулирования.

Опыт применения данного критерия эффективности показывает, что возникают значительные трудности только с определением величины $E_{2}$, которая в связи с отсутствием в настоящее время научно обоснованной методики её расчёта зачастую определяется со значительной погрешностью, что накладывает некоторые черты огрубления на конечные результаты. Тем не менее, это не может служить основанием для сомнений в необходимости утилитарного применения обобщающего универсализированного показателя.

С точки зрения системного подхода оценка систем управления объединениями (предприятиями) только по одному обобщающему критерию эффективности является недостаточной, так как научно-производственные объединения и промышленные предприятия, будучи сложными технико-экономическими и социальными системами, действуют в условиях ограничений, которые невозможно всесторонне учесть посредством одного критерия. Поэтому, при проектировании подсистемы (функции) целостного (интегрированного) экономического анализа и оценки необходимо наряду с обобщающим критерием эффективности использовать ещё и согласованные с ним частные критерии, удовлетворяющие одновременно нескольким целям подсистемы управления. То есть на практике процесс создания подсистемы администрирования сводится к решению задачи векторной оптимизации, существенным моментом которой является выбор решений, одновременно в максимально возмож- 
ной степени удовлетворяющих цели подсистемы по различным критериям эффективности. В качестве таких частных критериев эффективности могут быть приняты: частные экономические - прирост объёма процесса производства, повышение фондоотдачи, уменьшение материалоёмкости готовой продукции, рост производительности труда, снижение себестоимости готовой продукции и другие; частные технические снижение трудоёмкости экономико-аналитических расчётов, скорость обработки технико-экономической информации, точность получаемых итогов (результатов) и релевантность (уместность) информационных данных.

\section{вЫВОДЫ}

Следовательно, требование относительно возможности определения критерия эффективности функционирования при создании в функционально развитых системах стратегического регулирования специального назначения предприятиями самостоятельной функции интегрированного экономического анализа и оценки реализовывается совершенно и в исчерпывающем формате.

\section{Список использованных источников}

1. Ткаченко С.А. Розвиток систем економічної діагнос- тики в стратегічному менеджменті суб єктів агробізнесу: теорія, методологія, практика: дис. ... д-ра економ. наук: 08.00.04 / Харківський націон. технічний університет сільського господарства ім. Петра Василенка. Харків, 2017. $425 \mathrm{c}$.

2. Ткаченко С.А. Розвиток систем економічної діагностики в стратегічному менеджменті суб єктів агробізнесу: теорія, методологія, практика: автореф. дис. ... д-ра економ. наук: 08.00.04 / Харківський начіонал. техніч. ун-т сільського господарства ім. Петра Василенка. Харків, 2017. $36 c$.

\section{References}

1. Tkachenko S.A. Development of economic diagnostics systems in strategic management of agribusiness subjects: theory, methodology, practice: thesis for the degree of Doctor of Economic Sciences: 08.00.04 / Kharkiv Petro Vasylenko National Technical University of Agriculture. Kharkiv, 2017. 425 p.(in Ukrainian).

2. Tkachenko S.A. Development of economic diagnostics systems in strategic management of agribusiness subjects: theory, methodology, practice: Thesis for the degree of Doctor of Economic Sciences: 08.00.04 / Kharkiv Petro Vasylenko National Technical University of Agriculture. Kharkiv, 2017. 36 p. (in Ukrainian). 